Editorial

\title{
The Millennials in Medicine: Tips for Teaching the Next Generation of Physicians
}

\author{
Maria M. Aaron, MD ${ }^{1}$ Patricia Levenberg, $\mathrm{PhD}^{2}$ \\ ${ }^{1}$ Department of Ophthalmology, Emory University School of \\ Medicine, Atlanta, Georgia \\ ${ }^{2}$ Formerly of the Accreditation Council for Graduate Medical \\ Education, Review Committee for Ophthalmology, Chicago, Illinois \\ Journal of Academic Ophthalmology 2018;10:e38-e40.
}

A new generation of men and women, the Millennials, are entering our residency programs and clinical practices, and these young physicians learn and work in ways that are remarkably different than the cohorts of the past three generations. Therefore, it is important to have an understanding of the general characteristics of the Millennials and the other three generations because the differences, particularly in regard to the Millennials, will have a significant impact on both the delivery of health care and how the different generations interact within academic medical organizations. Next, one must then learn how to maximize the teaching and learning environment for the Millennials in our residency programs.

While it is important to understand the qualities of all four generations, one must keep in mind that not all individuals of a generation have precisely the same characteristics and many individual qualities are the result of parenting styles. There are currently four generations in the workforce: Traditionalists, Baby Boomers, Generation Xers, and Millennials. The Traditionalists, also known as the "silent generation," were born between 1925 and 1945. Typically they are "all work and no play" doctors. They are the Professor Emeriti and senior faculty members, who have wisdom, a strong work ethic, and loyalty to their jobs; you can count on them. However, they may lack knowledge of the latest technological advances and are often perceived as too formal.

Next, the Baby Boomers, born after World War II (between 1946 and 1964), are generally the midlevel and senior faculty members, often the leaders in our departments. The Baby Boomers are considered workaholics who are extremely dedicated, ambitious, idealistic, and competitive. Their careers often define them and provide their identity. Therefore, they have little understanding of work-life balance, another "all work and no play" group.

Declaring their independence, the Gen Xers were born between 1965 and 1979 and are mostly midlevel faculty

Address for correspondence

Maria M. Aaron, MD, Department

of Ophthalmology, Emory

University School of Medicine,

1365 Clifton Road, NE,

Atlanta, GA 30322

(e-mail: maria.aaron@emory.edu). members. They tend to be more cynical, distrust authority, and believe that there is more to life than work. Since they believe that family is a priority, they want balance between work and life and dislike rigid work requirements. They often seek out feedback and tend to rely on technology for communication more so than the Traditionalists or Boomers.

Finally, the Millennials, or Generation Y, our current junior faculty, residents, and medical students, were born between 1980 and 2001. These individuals grew up in a booming economy and therefore are often accustomed to the best. They have been called the "child-centric generation" because they were raised with close parental involvement (the so-called helicopter parents). Millennials have many positive attributes, such as being team oriented, safety oriented, optimistic, civic minded, and want to make the world a better place. They desire immediate access to technology, tend to have shorter attention spans, and necessitate talented instructors to persuasively engage them. ${ }^{1}$

Armed with solid demographic information, a good teacher can create learning activities and bedside instruction based on the traits that most characterize the generation. Our standard approaches to educating residents are no longer ideal. Our newest learners in the healthcare arena require novel approaches to feedback, mentoring, teaching and learning, and work-life balance. If faculty wants to succeed in ensnaring this group, they must get creative with their approach to learning.

\section{Feedback and Mentoring}

Using appropriate strategies for feedback to Millennials, who are new to the professional arena, will generally create a more positive learning environment. First, it is essential to create a culture of feedback from the first day in the residency program. One must act as a mentor and explain to residents that they will, without a doubt, receive criticism throughout their training to make them the best doctors

Copyright $\odot 2018$ by Thieme Medical Publishers, Inc., 333 Seventh Avenue, New York, NY 10001, USA.

License terms

DOI https://doi.org/ ISSN 2475-4757.

Tel: +1(212) 584-4662.

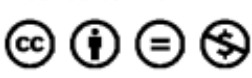


possible. It is essential that faculty remind them of this fact many times throughout their residency. At the same time, it is important to provide a set of expectations that will guide the development of the residents' attitudes, knowledge, and skills. ${ }^{2}$

As mentioned previously, the Millennials are "success stories" with impressive resumes reflecting confidence, accomplishments, and intelligence. ${ }^{3}$ They want to do it right the first time. Because of these early experiences, they may interpret negative feedback as failure and may not be aware or even recognize their own poor performance. At the same time, Boomers and Gen Xers may be uncertain as to how to provide constructive feedback to this generation and to acknowledge the difference in learning preferences. One should give praise when the resident truly deserves it but provide negative feedback privately because acceptance and others' perception of them are highly important to this generation. Methods of feedback that worked well with prior generations (i.e., the Traditionalist's "boot camp style" where no news is good news or the Gen-Xer's blunt and undiplomatic feedback) do not tend to work well with the Millennials.

The Millennial track record of success, accomplishment, and self confidence doesn't have to be maladaptive. It also keeps them driving forward toward continued success in their future. In fact, it can be protective, keeping the young person from falling apart during uncertainty and when the going gets tough.

These young men and women want to have a close relationship with the program director and faculty. They crave constant communication and connection. Millennials are accustomed to "coaching" or "parenting" styles of feedback along with a lot of encouragement. This is best achieved by taking a personal interest in the resident, and helping them develop the necessary skills to be successful along the way. Since the Traditionalists and Boomers often have children who are of the age of residents, they are naturally excellent mentors and often quite skilled at providing this feedback. Another approach to mentoring is "Peer Mentoring" where groups of peers work together to address professional development. The "360 Degree Evaluation," which often provides the most reliable feedback of a resident, is a form of peer mentoring that may be highly effective in your residency program. Finally, experience suggests that "group mentoring" when one or two more senior faculty meet with more junior faculty/residents as a group is an effective form of feedback. This diffuses the "chain of command," reduces emphasis on any one individual, and reduces time burden on any single faculty member. An invitation to a pot luck dinner at your home can go a long way to promoting a strong relationship within the residency.

\section{Teaching and Learning Styles}

Teaching and assessing learning in a multigenerational environment can be challenging and therefore requires careful contemplation. The challenge arises when the educator attempts to teach the Millennials by using teaching techni- ques that worked for his/her generation but clearly do not work for these young individuals.

The Traditionalists prefer the "traditional" classroom structure with lecture presentation and use of the Socratic process for classroom learning, while the Boomers tend to enjoy lots of interaction and "talk" time and prefer a spirit of collegiality. Gen Xers who are often impatient prefer to get to the point and move on as soon as possible. The Millennials are less accepting of these traditional teaching methods. If one is serious about engaging these learners, they will have to create an experience the learners will want to share. By focusing efforts on experiential learning and incorporating a sense of responsibility, the teacher will better connect with these learners.

The learning style of the Millennial is quite different than the other generations. Millennials are intuitive visual communicators and when they must hear a lecture, these learners respond to pictures, graphics, and short video segments like those found on YouTube. In addition, they are explorative, experiential, hands-on learners, who learn better by discovery than being told.

While many Millennials are highly intelligent, they may also have little desire to listen to long lectures or read long texts. ${ }^{4}$ Lecturers should consider delivering talks in shorter segments and incorporate more material that can be delivered via media such as videos and interactive formats. While many question the Millennials' ability to multitask, it is certainly true that they can shift their attention easily from one thing to another. While they may think nothing of sending a text message during a lecture, or researching a diagnosis at the bedside, their "multitasking" may be considered rude or that of disinterest. In addition, they prefer educational material that can be delivered to the device in front of them. Therefore, it is essential that educators incorporate up-to-date technology, such as online modules and Podcasts, into learning. Lastly, Millennials enjoy a "blended" education, education that is also entertaining, referred to as "edutainment." ${ }^{5}$ Using gamification as well as team-based and case-based competitions are highly successful in engaging the Millennial learner.

Educating Millennials in the classroom carries its own set of challenges, but teaching residents in the clinic also requires new strategies. First, it is important for the program director to provide explicit and clearly stated goals and expectations for the residents. The Millennials respond well to very specific instructions, especially when the relevance of the material is also explained. They learn best when the learning activities are structured and more interactive. While they prefer to have all the answers immediately at hand, the practice of medicine does not always provide that opportunity. Therefore, it is essential that we teach resourcefulness and remind the residents that sometimes information is lacking, decisions are complex, and the diagnosis in not clear. Since Millennials are extraordinary team players, we should encourage them to find solutions as a team. In addition, Millennials appreciate checklists when appropriate because the structure provides them with clear expectations and goals to achieve. This 
same structure should also be provided in educational objectives, handbooks, dress code, as well as email, telephone, and texting etiquette. It is often useful in a residency program to offer workshops on communicating with faculty and patients across generations. ${ }^{6}$

In summary, Millennials are accustomed to group work, comfortable with active learning, and multitask with ease. They are technological experts, goal and achievement oriented, and enjoy personal interaction and a sense of community. These strengths can be emphasized by using the Millennials to provide technology tutorials to older generations and tap into their global connections for research, information, and education.

\section{Work-Life Balance}

One of the biggest challenges that we face as teachers of medicine is the emphasis of the Millennials on work-life balance. It is often referred to as "work-life blend" because this generation tends to blend personal interests into the workday, and work activities into the evenings. While this may work satisfactorily in the business world, it presents challenges in medicine because of medical emergencies and responsibility to patients. With the increased emphasis on duty hours and physicians' desire for more clearly defined work hours, medicine is naturally developing a more "shiftwork" mentality which lends itself nicely to the priorities of the residents. ${ }^{7}$ In addition, this generation will be instrumental in finding solutions to the significant concerns regarding physician burnout and depression.

At the same time, more women are graduating from medical schools and have the added responsibility of childbearing, and today's parents are in many cases equally responsible for child care. Changes in the medical culture, such as duty hour regulations, night float systems, and additional physician extenders, are encouraging more balance in residents' lives. These trends lead to a more teambased approach to health care delivery, where nurse practitioners, technicians, and physician assistants share and take greater responsibility for patient care.

In the recent Flexner report, Changes in Physician Culture: 1910 versus 2010 Flexner Report, it is reported that the 20th century physician was more of an individual scholar or solo expert who worked in a physician-centered environment. These doctors worked autonomously, accumulated knowledge, and worked toward individual achievement. In contrast, the 21 st century physicians now work in interdisciplinary teams and coordinate patient care in a patient-centered environment. These physicians acquire and use knowledge, collaborate with other healthcare providers, and have a shared accountability for patient care. ${ }^{8}$

As the individual resident prefers a work-life blend, residency program directors must find innovative ways to provide patient care and yet allow residents the balance and time for rest and family. Programs should have systems in place to manage emergencies and have clearly defined leave policies so that residents understand the procedures that are to be followed when they have a sick parent or child that requires attention. Resource guides with clearly defined policies and information about childcare, pediatricians, babysitting, wellness centers, etc., are extremely valuable to residents and program directors. In addition, hospitals may soon develop more family and employee friendly arrangements for resident physicians. It must be a priority for all of us to reduce rates of burnout, focusing on wellness and joy in medicine. This, in turn, will provide higher patient satisfaction scores and fewer rates of medical errors with less turnover among physicians. Finally, the Millennials are a global and generous generation who thrive on opportunities for medical missions. Providing opportunities for overseas missions also encourages work-life balance and a sense of the greater healthcare community.

The diversity of generational values that exist in the medical centers creates occasional challenges, but provides many opportunities. An understanding of the Millennial's life experiences will assist faculty in being leaders and mentors to this group. The Millennials fit nicely into the changing healthcare environment in many ways. Their notions of teamwork, technological acumen, and generosity will be beneficial to older physicians and the changing healthcare environment. These new physicians will force faculty to sharpen communication skills, particularly with social networking and more interactive educational formats. Lastly, this young generation will be highly instrumental in finding creative ways to provide more opportunities for wellness in medicine. Learning to identify generational differences and apply strategies to overcome differences will promote and improve learning environments for all generations, which will ultimately improve patient care.

\section{References}

1 Zemke R, Raines C, Filipczak B. Generations at Work: Managing the Clash of Veterans, Boomers, Xers, Nexters in Your Workplace. New York: AMACON; 2000

2 Epstein M, Howe P. The Millennial generation: recruiting, retaining and managing. Today's CPA 2006;September/October:24-27

3 Alsop R. The Trophy Kids Grow Up, “How Am I Doing?" San Francisco: Jossey-Bass; 2008

4 Twenge JM. Generational changes and their impact in the classroom: teaching Generation Me. Med Educ 2009;43(05):398-405

5 Oblinger D, Oblinger J. Educating the Net Generation, eBook. Louisville, CO: Educause; 2005

6 Oblinger D. Boomers, Gen-Xers \& Millennials: understanding the new students. Educause 2003;38(04):37-46

7 Drolet BC, Khokhar MT, Fischer SA. The 2011 duty-hour requirements-a survey of residency program directors. N Engl J Med 2013;368(08):694-697

8 Morrison G, Goldfarb S, Lanken PN. Team training of medical students in the 21st century: would Flexner approve? Acad Med 2010;85(02):254-259 